VITAL DA CUNHA, Christina; LOPES, Paulo Victor Leite. Religião e Política: uma análise da atuação de parlamentares evangélicos sobre direitos das mulheres e de LGBTs no Brasil. Rio de Janeiro: Fundação Heinrich Böll, 2012, 232pp.

\title{
Poder e Medo: os evangélicos na política e o combate À AGENDA FEMINISTA NO BRASIL
}

\section{Edilson Pereira}

De acordo com o IBGE (2010), um em cada cinco brasileiros se identifica atualmente como evangélico. A tendência de crescimento desse segmento religioso observada nas últimas décadas tem feito com que os pesquisadores interessados no tema da religião e da política no país passem a considerar, cada vez com mais ênfase, a importância dos evangélicos nas transformações culturais do Brasil recente. Assim é que os antropólogos Christina Vital da Cunha e Paulo Victor Leite Lopes realizaram o estudo que resultou na publicação Religião e Política: uma análise da atuação de parlamentares evangélicos sobre direitos das mulheres e de LGBTs no Brasil.

Partindo do reconhecimento da complexidade que caracteriza o interior do universo evangélico, os autores desenvolveram um estudo que leva em conta os diferentes grupos sociais com os quais os líderes religiosos interagem. Através de fontes primárias e secundárias (incluindo jornais e revistas de grande circulação no país), Vital da Cunha e Lopes reportam-se à vasta rede formada por políticos religiosos e não-religiosos, assessores parlamentares, líderes de diferentes igrejas, representantes do terceiro setor/ ONGs, jornalistas etc. que, através de suas declarações e atividades retratadas pela mídia, geram um rico objeto de pesquisa - cujo material preliminar foi identificado por uma equipe de pesquisadores do Instituto de Estudos da Religião (ISER) em parceria com a Fundação Heinrich Böll Brasil.

O livro permite ao leitor acompanhar um universo cheio de vozes dissonantes, no qual referências culturais, sociais e políticas misturam-se em meio a estratégias de disputa e exploração de temas importantes para o avanço de direitos de diferentes grupos. Inicialmente, ao abordar o tema da laicidade e das várias modalidades de presença do religioso no espaço público brasileiro, os autores intercalam dados contemporâneos com informações históricas, para evidenciar como a inserção dos evangélicos no campo das disputas políticas, ao longo das últimas décadas, teria tornado explícita uma 
longa relação mantida entre o poder estatal brasileiro e a Igreja Católica. Dessa forma, Vital da Cunha e Lopes indicam que os evangélicos não seriam uma (nova) exceção à regra; ao contrário, eles reforçariam os vínculos já existentes, ainda que os adequando às suas próprias demandas - expressas através de suas alianças (inclusive com políticos e grupos não religiosos) e das Frentes Parlamentares.

A análise da estruturação evangélica na Câmara dos Deputados e no Senado é acompanhada pelo estudo da configuração particular desse universo religioso. E, para tanto, os autores apresentam as classificações operatórias que distinguem os evangélicos entre si, destacando o lugar ocupado pelos pentecostais e neopentecostais nas mídias e no espaço público. Nesse sentido, eles abordam duas igrejas de grande peso relativo no campo religioso e político: a Assembleia de Deus, que se constitui atualmente como a maior igreja evangélica em número de fiéis do país, com mais de 12 milhões de adeptos; e a Igreja Universal do Reino de Deus, que ganhou grande visibilidade pelo sucesso de seus empreendimentos religiosos e midiáticos, além das polêmicas e denúncias envolvendo seu fundador.

Conscientes das inúmeras fissões existentes entre as igrejas evangélicas, os autores escolheram alguns casos exemplares para demonstrar, não obstante, como os seus líderes "vêm atuando unidos em prol da promoção de uma sociedade moralizada e civilizada a partir de seus termos" (:180).

O primeiro desses casos trata da controvérsia em torno do aborto na disputa eleitoral de 2010, quando Dilma Rousseff foi eleita presidente do Brasil. Às vésperas das eleições, uma série de reportagens e declarações reforçavam a ideia do "poder" associado ao "voto evangélico", bem como divulgavam acusações e "boatos" que passaram a pautar parte das campanhas dos candidatos. Em dado momento da disputa, Dilma, José Serra e Marina Silva passaram a ser relacionados (seja por suas coalisões, ou por suas disputas) a diferentes líderes religiosos, como o bispo católico Luiz Gonzaga Bergozini, de Guarulhos-SP, e o pastor da Assembleia de Deus, Silas Malafaia. Esses últimos, por exemplo, acusavam a então candidata que despontava como líder das intenções de voto, bem como ao Partido dos Trabalhadores (PT), de ser favorável à descriminalização do aborto. O tema, que não fazia parte do programa de governo de nenhum dos candidatos, tornou-se um assunto recorrente na mídia e elevou certos líderes religiosos à posição de interlocutores privilegiados. Quando a disputa se concentrou entre José Serra e Dilma, houve um nítido direcionamento nas campanhas de ambos, de modo a afiná-las com as "demandas" religiosas. Nesse contexto, era comum vê-los agradecendo a Deus em seus discursos públicos e em comunicações oficiais. Através de uma descrição densa, os autores mostram como, nessa polêmica em torno do aborto, a propaganda sobre a importância dos religiosos na disputa eleitoral fazia parte do próprio jogo político em questão.

No capítulo seguinte, um outro caso-chave é analisado para se pensar as relações mantidas entre deputados, senadores, líderes religiosos e ativistas políticos: a polêmica envolvendo o material didático intitulado "Escola Sem Homofobia", 
elaborado pelo Ministério da Educação e vulgarizado pela mídia como "kit-gay" ou como "kit anti-homofobia". Como apontam os autores, a própria pluralidade de nomes atribuídos ao material escolar, desenvolvido para ser aplicado primeiramente junto a professores da rede pública de ensino, revela as dissonâncias existentes entre os diferentes personagens que participaram dessa controvérsia ocorrida entre o final de 2010 e início de 2011. Embora o material fizesse parte do Programa Brasil Sem Homofobia, que vem sendo desenvolvido desde 2004 com o propósito de elaborar políticas públicas de combate à violência contra a população LGBT, ele se tornou objeto de inúmeras críticas nessa época, dentre as quais se destacaram as do deputado federal Jair Bolsonaro. Sem identificar-se necessariamente como um político religioso, ele afirmava ser "um absurdo" o modo como o governo estaria produzindo um material de "propaganda do homossexualismo", que seria direcionado indistintamente para as crianças pequenas, para os "nossos filhos!".

Intercalando as falas de diferentes atores, Vital da Cunha e Lopes mostram como figuras públicas como Bolsonaro se aliaram à bancada evangélica para formar um grupo de pressão política. Contudo, segundo os autores, essa estratégia de ação não teria obtido os efeitos alcançados (de proibição da distribuição do material educativo) se não fosse um outro fato político que colocava o governo de Dilma, recém-eleita, em xeque: as denúncias de corrupção atribuídas a Antonio Palocci (PT), então chefe da Casa Civil. O jogo de influências e a realização de pactos de silêncio fizeram com que o governo federal se rendesse às demandas das bancadas religiosas, contrariando uma grande parte da base aliada e o movimento LGBT.

Tanto no caso da polêmica do aborto, quanto no do material educativo, os autores mostram que as relações políticas analisadas não se configuram em uma oposição binária entre atores religiosos e não-religiosos, e que, além disso, "o que se apresenta como central [nos dois casos] são as tensões em busca da definição de uma política sexual no Brasil" (:119). A partir da instrumentalização da política, líderes evangélicos e seus apoiadores passaram a acionar "pânicos morais", através da divulgação de informações incorretas e/ou incompletas sobre temas de grande repercussão social.

Os líderes religiosos trabalhariam, assim, com a promoção do medo generalizado sobre tais temas. $\mathrm{O}$ medo se daria, por exemplo, em relação à destruição da "ordem das coisas", que poderia ocorrer caso os direitos e as políticas públicas demandadas pelos grupos feministas e LGBTs fossem reconhecidos pelo governo. Um termo chave que aparece nesse ambiente é a noção de "família", ou, nas palavras de um senador evangélico, a "família assim como Deus a constituiu". O avanço de demandas sociais poderia abalar a "família brasileira" - uma categoria que, ao meu ver, parece ser central nesse ambiente pesquisado, na medida em que condensa a referência política e religiosa simultaneamente. Não obstante à riqueza da análise das polêmicas citadas, tal noção nativa não chega a ser alvo de maior atenção durante a descrição das técnicas de articulação política dos religiosos no Congresso. 
Outro ponto que gostaria de destacar - e que talvez esteja condicionado mais à minha leitura particular da obra do que a ela em si - tem relação com o fato de que embora a pesquisa ofereça as condições ideais para a realização de uma pertinente crítica dos efeitos dos jogos de poder apresentados, esse posicionamento não se realiza explicitamente. Talvez para evitar uma abordagem "caricatural" do objeto de pesquisa, a análise aponte mais para os evangélicos compreendendo-os como "um grupo de pressão entre tantos outros" em ação atualmente.

Acontece que, se, por um lado, esse posicionamento metodológico expressa uma preocupação relativizadora em relação ao objeto pesquisado, por outro, os autores acabam assumindo o pressuposto, expresso desde o início do livro, de que "os religiosos operam com as mesmas categorias, mobilizando um conjunto de argumentos que é também utilizado por aqueles que desejam garantir a separação institucional entre Estado, política e religião no Brasil”. Essa linha de raciocínio, quando aproximada das descrições dos casos relatados, resulta numa curiosa composição, na qual os dois lados de uma luta política (que podemos identificar esquematicamente como 'evangélicos' versus 'mulheres e LGBTs') assumiriam as mesmas categorias para se contraporem.

Um dos problemas derivados dessa equivalência (improvável) entre tais grupos é que ela implica na suposição de que as categorias que eles utilizam seriam fixas, dado que são "comuns" a ambos. Ora, se os repertórios desses grupos antagônicos contêm termos compartilhados, talvez isso se deva justamente à relação particular e específica de contraposição em que eles se encontram - justamente o que os autores descrevem - e não à estabilidade dos termos em si. Em outras palavras, assim como eles desconstroem a imagem da "força evangélica" em relação à eleição de 2010, os autores também poderiam ter questionado a inclinação evangélica à "laicidade" (tomada a partir de suas definições não-religiosas), assim como tantas outras declarações nativas, como é o caso de eles se afirmarem como "mais um grupo" de articulação política, entre outros.

Quando um senador-pastor, contrapondo-se a uma política educativa pública contra a discriminação sexual, defende enfaticamente que "Deus criou o macho e a fêmea. Não vai ser o Senado da República que vai criar o terceiro sexo" (:132), ele não se apresenta apenas como um opositor dos interesses de grupos políticos distintos do seu. Ele se contrapõe àquela casa em si, dada sua condição de território instituído da política (e não da religião), e, além disso, recusa qualquer possibilidade de direito ao "terceiro sexo", tomado como tudo aquilo que está fora da "ordem" [evangélica] das coisas. A esse outro não se dá sequer o direito de existência - excluído, portanto, da "família" de iguais. Ele está fora da natureza, fora da política, fora da democracia.

A demanda pela continuidade da crítica, no entanto, ocorre após o mergulho no amplo repertório que é oferecido pelos autores. Como resultado de sua análise, eles trazem uma importante atualização das pesquisas sobre um campo em 
contínuo reajuste e disputa. Sem dúvida, trata-se de uma leitura que permite abrir novas questões para refletirmos sobre os desafios da análise sócio-antropológica sobre as atividades política e religiosa no Brasil recente.

***

Edilson Pereira (edilperei@yahoo.com.br) Doutorando em Antropologia Social pelo PPGAS do MN/UFRJ. 